\title{
Nitric Oxide-generating Vasodilators and 8-Bromo-Cyclic Guanosine Monophosphate Inhibit Mitogenesis and Proliferation of Cultured Rat Vascular Smooth Muscle Cells
}

\author{
Uttam C. Garg and Aviv Hassid \\ Department of Pharmacology, University of Tennessee, Memphis, Tennessee 38163
}

\begin{abstract}
Endothelium-derived relaxing factor has been recently identified as nitric oxide. The purpose of this study was to determine if vasodilator drugs that generate nitric oxide inhibit vascular smooth muscle mitogenesis and proliferation in culture. Three chemically dissimilar vasodilators, sodium nitroprusside, $S$-nitroso- $N$-acetylpenicillamine and isosorbide dinitrate, dose-dependently inhibited serum-induced thymidine incorporation by rat aortic smooth muscle cells. Moreover, 8-bromo-cGMP mimicked the antimitogenic effect of the nitric oxide-generating drugs. The antimitogenic effect of $S$-nitroso- $N$-acetylpenicillamine was inhibited by hemoglobin and potentiated by superoxide dismutase, supporting the view that nitric oxide was the ultimate effector. Sodium nitroprusside and $S$-nitroso- $N$ acetylpenicillamine significantly decreased the proliferation of vascular smooth muscle cells. Moreover, the inhibition of mitogenesis and proliferation was shown to be independent of cell damage, as documented by several criteria of cell viability. These results suggest that endogenous nitric oxide may function as a modulator of vascular smooth muscle cell mitogenesis and proliferation, by a cGMP-mediated mechanism.
\end{abstract}

\section{Introduction}

Vasodilation, induced by acetylcholine, bradykinin, ATP, histamine, vasoactive intestinal polypeptide (VIP), ${ }^{1} \mathrm{~A} 23187$ and leukotrienes, among others, is dependent on the presence of endothelium (1-3). The substance evoking these relaxations has been termed endothelium-derived relaxing factor (EDRF) and has been recently identified as nitric oxide (NO) (4-8). The actions of EDRF appear to be mediated by cGMP, inas-

The present address of Dr. Garg and Dr. Hassid is Department of Pharmacology, New York Medical College, Valhalla, NY 10595. Address reprint requests to Dr. Hassid.

Received for publication 4 November 1988 and in revised form 30 January 1989.

1. Abbreviations used in this paper: EDRF, endothelium-derived relaxing factor; ISDN, isosorbide dinitrate; NO, nitric oxide; SNAP, $S$-nitroso- $N$-acetylpenicillamine; SNP, sodium nitroprusside; VIP, vasoactive intestinal polypeptide.

J. Clin. Invest.

(C) The American Society for Clinical Investigation, Inc.

0021-9738/89/05/1774/04 \$2.00

Volume 83, May 1989, 1774-1777 much as EDRF increases vascular cGMP and cGMP analogues as well as agents that increase cGMP mimic the actions of EDRF (9-12). In addition, pharmacologic inhibition of the increase of cGMP induced by EDRF attenuates its vasodilatory effect (13).

Recently, our laboratory has shown that atrial natriuretic hormone decreases serum-stimulated DNA synthesis and proliferation of cultured mesangial cells (14). These cells share many characteristics with systemic vascular smooth muscle cells, including contractile activity. Atrial natriuretic hormone and NO both have the ability to increase vascular cGMP, and based on this observation, we speculated that NO-generating vasodilators would inhibit the mitogenesis and proliferation of vascular smooth muscle cells. We now report that three such structurally dissimilar drugs, as well as 8-bromo-cGMP, effectively inhibit DNA synthesis and proliferation of rat aortic smooth muscle cells in culture.

\section{Methods}

$S$-Nitroso- $N$-acetylpenicillamine (SNAP) was synthesized according to the method of Field et al., by reaction of $\mathrm{NaNO}_{2}$ and $\mathrm{N}$-acetylpenicillamine, at low $\mathrm{pH}$ (15). The chemical purity of the product was established by thin-layer chromatography on silica gel-GF (Analtech, Newark, DE) with $\mathrm{CHCl}_{3}: \mathrm{CH}_{3} \mathrm{OH}: \mathrm{H}_{2} \mathrm{O}(7: 3: 0.3 / \mathrm{vol} / \mathrm{vol} / \mathrm{vol})$ as the solvent system (single spot with $R_{\mathrm{f}} \sim 0.6$ ), and by determination of the melting point which was found to be $149^{\circ}-151^{\circ} \mathrm{C}$, similar to the previously reported value of $152^{\circ} \mathrm{C}(15)$. Additionally, SNAP was found to have a nuclear magnetic resonance spectrum consistent with the expected chemical structure (results not shown). Sodium nitroprusside (SNP), isosorbide dinitrate (ISDN), and 8-bromo-cGMP were purchased from Sigma Chemical Co. (St. Louis, MO).

Rat aortic smooth muscle cells were isolated and cultured, as previously described (16). For the measurement of thymidine uptake, cells, used between the 4 th and 11 th subculture, were seeded at a density of $\sim 2 \times 10^{-4} \cdot \mathrm{cm}^{-2}$ and cultured for 2-5 d in RPMI 1640 medium supplemented with $20 \%$ heat-inactivated fetal bovine serum (Gibco Laboratories, Grand Island, NY), insulin ( $5 \mu \mathrm{g} / \mathrm{ml})$, transferrin $(5 \mu \mathrm{g} / \mathrm{ml})$, and selenous acid $(5 \mathrm{ng} / \mathrm{ml})$ (Collaborative Research, Lexington, MA) plus antibiotics. To achieve quiescence, aortic smooth muscle cells were washed, three times, with serum-free medium and cultured for $2 \mathrm{~d}$ in the same medium further supplemented with $0.5 \%$ albumin. To investigate the effect of various agents on mitogenesis, quiescent cells were cultured for $20 \mathrm{~h}$ in medium supplemented with or without $5 \%$ serum, containing or lacking experimental agents. Finally, cells were incubated for $2 \mathrm{~h}$ in freshly prepared media that were additionally supplemented with $\sim 1 \mu \mathrm{Ci}\left[\right.$ methyl $\left.-{ }^{3} \mathrm{H}\right]$ thymidine $(7-20$ $\mathrm{Ci} \cdot \mathrm{mmol}^{-1}$; New England Nuclear, Boston, MA), to measure DNA synthesis by thymidine incorporation. The experiments were terminated by washing cells with $1 \mathrm{mM}$ Ca-supplemented PBS, precipitation of acid-insoluble material with 10\% TCA and extraction of the DNA 


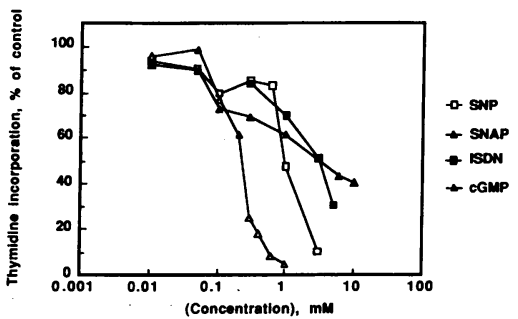

Figure 1. Dose-response relationships for the inhibition of serum-induced thymidine incorporation by SNAP, ISDN, SNP, and 8bromo-cGMP. Results are the mean of three to six separate experiments, each in quadruplicate. Results are expressed as percentage of control, defined as thymidine incorporation in the presence of $5 \%$ serum only. For the sake of clarity, standard errors were omitted from the figure but they were $<10 \%$ of control except for those at 0.2 and 0.3 mM SNAP, which were $18.8 \%$ and $12.6 \%$ of control, respectively.

with $0.1 \% \mathrm{SDS} / 0.5 \mathrm{~N} \mathrm{NaOH}$. The radioactivity of an aliquot of the extract was measured by scintillation counting.

To determine the effect of experimental agents on cell growth, cells were seeded at a density of $\sim 6 \times 10^{2} \cdot \mathrm{cm}^{-2}$ and cultured for $2 \mathrm{~d}$ in medium supplemented with $20 \%$ serum. Cells were then cultured, for 2 $\mathrm{d}$, in serum-free medium in order to induce cell quiescence. This was followed by culture for $6 \mathrm{~d}$ in medium supplemented with $5 \%$ serum, containing or lacking experimental agents. Culture media were changed daily and cell numbers were determined by dissociation of adherent cells with trypsin and counting with a hemacytometer.

Statistical comparisons were performed by the use of unpaired, two-tailed Student's $t$ test, or analysis of variance, as appropriate.

\section{Results}

SNP and ISDN are drugs that generate NO spontaneously or by intracellularly catalyzed reactions $(9,11)$. SNAP is a similar experimental drug which spontaneously releases NO in aqueous medium (9). The actions of these drugs on thymidine incorporation into quiescent cultured aortic smooth muscle cells were therefore evaluated. Serum stimulated thymidine incorporation by 15-20-fold, relative to serum-lacking medium (not shown), whereas all three NO-generating vasodilators dose-dependently inhibited the incorporation of thymidine (Fig. 1). SNAP was most potent, followed by SNP and ISDN. At the highest concentrations used, SNAP and SNP almost completely inhibited serum-induced thymidine incorporation.

Inasmuch as the effects of the above mentioned vasodilators are generally thought to be mediated by cGMP as the second messenger, we also tested the effect of 8-bromo-cGMP on serum-induced thymidine incorporation. As shown in Fig. 1, 8-bromo-cGMP dose-dependently inhibited serum-stimulated thymidine incorporation.

Hemoglobin is well established as antagonist of the actions of EDRF/NO, by trapping and/or oxidation $(17,18)$. To further identify the agent inducing antimitogenesis, we compared the dose-response relationship of SNAP-induced antimitogenesis in the presence or absence of hemoglobin. Hemoglobin itself had very little effect on serum-induced mitogenesis, decreasing it by $14.3 \%(n=3)$. However, as indicated in Fig. 2, the dose-response relationship for SNAP-induced inhibition of mitogenesis was shifted to the right by almost an order of magnitude, indicating antagonism of SNAP's antimitogenic activity by hemoglobin.

A second agent that can alter NO levels in aqueous media is $\operatorname{SOD}(4,6,19)$. Superoxide anions, which are spontaneously

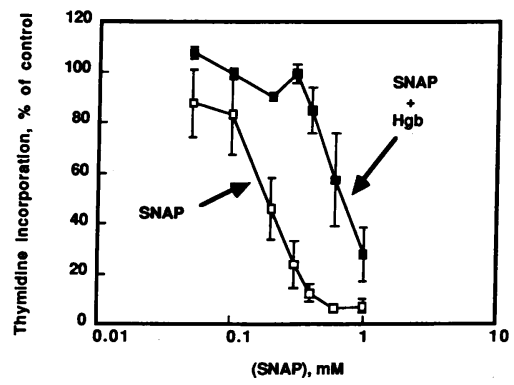

Figure 2. Effect of hemoglobin $(50 \mu \mathrm{M}, \mathrm{Hgb})$ on the inhibition of mitogenesis induced by SNAP. Open squares indicate the effect of SNAP alone, while closed squares indicate the effect of SNAP in the presence of hemoglobin. Results are the mean \pm SE of three sepa-

rate experiments (each in quadruplicate) and the difference between the two curves was significant at $P<0.001$, by analysis of variance. Standard errors are not shown when their magnitude is less than the width of the symbol.

generated in oxygen containing media, have the ability to oxidize NO and therefore to decrease its concentration; SOD inhibits or prevents this effect by catalyzing the degradation of superoxide. SOD alone caused a 5\% decrease of serum-stimulated thymidine incorporation but, as shown in Fig. 3, it caused significant potentiation of the antimitogenic activity of SNAP, particularly at low concentrations of SNAP, further supporting the notion that NO was the ultimate effector of antimitogenesis.

The inhibition of DNA synthesis by NO-generating agents indicated that these agents should also inhibit cell proliferation. We tested the effect of the two most potent vasodilators, SNAP and SNP, on the rate of serum-induced cell proliferation. As shown in Fig. 4, both SNAP and SNP significantly inhibited the rate of aortic smooth muscle cell proliferation.

A trivial explanation of the antimitogenic effect of NOgenerating agents is that it is the result of the degradation of serum mitogens by a free radical-mediated mechanism. To rule out this possibility, we preincubated serum-containing culture medium with $1 \mathrm{mM}$ SNAP (highest concentration used in our experiments) for $3 \mathrm{~d}$. The half-life of SNAP in aqueous medium has been determined to be $\sim 5 \mathrm{~h}(9)$, and we reasoned that after $3 \mathrm{~d}$ of preincubation, almost all SNAP would be degraded to products that are thought to include the dimer of $\mathrm{N}$-acetylpenicillamine as well as nitrite and nitrate (9). Preincubated SNAP ( $1 \mathrm{mM})$ decreased thymidine incorporation by $37.5 \pm 2.4 \%(n=3)$, relative to serum-containing medium preincubated without SNAP for $3 \mathrm{~d}$, whereas culture

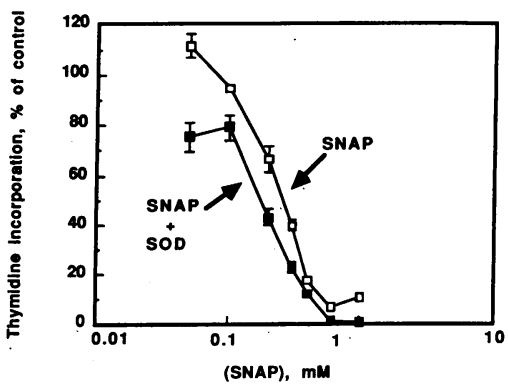

Figure 3. Effect of SOD $(100 \mathrm{U} / \mathrm{ml})$ on the inhibition of mitogenesis induced by SNAP. Open squares indicate the effect of SNAP alone, while closed squares indicate the effect of SNAP in the presence of SOD. Results are the mean $\pm \mathrm{SE}$ from one experiment, in quadruplicate. The difference between the two curves was significant at $P<0.001$, by analysis of variance. Standard errors are not shown when their magnitude is less than the width of the symbol. Similar results were also obtained in a second experiment. 


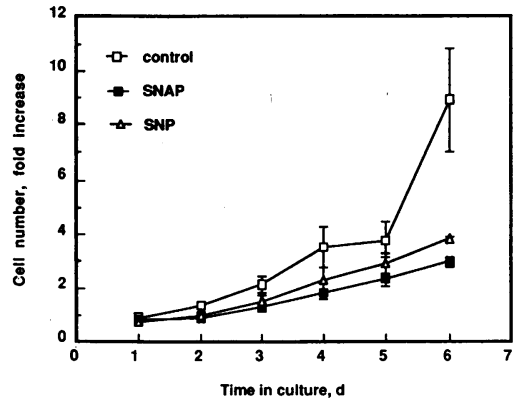
growth curves in the presence of SNAP or SNP and control was significant $(P<0.01)$ by analysis of variance.

medium containing the same concentration of fresh SNAP inhibited thymidine incorporation by $94.6 \pm 1 \%(n=3)$.

It is also possible that the antiproliferative effect of NOgenerating agents is the result of loss of cells due to toxicity. To rule out this possibility the following series of experiments was performed: $(a)$ The number of cells present in the supernatant media was determined daily for $6 \mathrm{~d}$, both in the presence and absence of $0.1 \mathrm{mM}$ SNAP. While this concentration of SNAP caused significant inhibition of cell growth, $<1 \%$ of cells were found to be present in the supernatant during any portion of the culture period. Thus, detachment and loss of cells did not account for inhibition of cell proliferation. It should be noted that increasing the concentration of SNAP above $0.1 \mathrm{mM}$ did cause the loss of cells after several days in culture, indicating possible toxicity in long-term experiments at high concentrations of SNAP.

Incubation of aortic smooth muscle cells for $22 \mathrm{~h}$ with 1 mM SNAP also caused no significant cell loss: the number of cells was $3.0 \pm 0.2 \times 10^{5}(n=4)$ in control wells and $2.9 \pm 0.1$ $\times 10^{5}(n=4)$ in SNAP-treated wells; moreover, no significant release of lactate dehydrogenase was observed in this experiment, again indicating that in short-term incubations, even high concentrations of SNAP do not induce cell damage. (b) Cells were cultured for $6 \mathrm{~d}$ in medium containing or lacking $0.1 \mathrm{mM}$ SNAP and lactate dehydrogenase levels in the supernatants were determined, daily. No significant release of lactate dehydrogenase was observed during the entire culture period. (c) Less than $1 \%$ of the cells treated with 0.1 mM SNAP for $6 \mathrm{~d}$ or $1 \mathrm{mM}$ SNAP for $22 \mathrm{~h}$, stained with trypan blue.

\section{Discussion}

Recently, we reported that atriopeptins 28 and 24 inhibit serum-induced thymidine incorporation and proliferation of mesangial cells (14). Inasmuch as atriopeptins are believed to exert most of their biological effects by raising intracellular cGMP, we intended to test the hypothesis that nitric oxidegenerating agents that are well documented to increase cGMP, would also inhibit DNA synthesis and proliferation of smooth muscle cells. In this study we report that three chemically dissimilar, NO-generating vasodilators effectively inhibit DNA synthesis and proliferation of rat aortic smooth muscle cells. This effect was dose dependent, with the order of potency being SNAP > SNP > ISDN.

The two most potent antimitogens, SNAP and SNP, were tested for their ability to inhibit the proliferation of aortic smooth muscle cells. As expected, both drugs significantly decreased the rate of serum-induced aortic smooth muscle proliferation, consistent with the finding that they inhibited DNA synthesis.

That the antimitogenic and antiproliferative effects of NOgenerating agents were likely to be due to the action of NO itself was indicated by the decreased potency of SNAP in the presence of hemoglobin. The ability of hemoglobin to inhibit EDRF activity and to trap NO has been shown previously by several groups of investigators $(17,18)$. That the maximal effectiveness of SNAP was not affected by hemoglobin could be attributed to the ability of high concentrations of SNAP to generate sufficient NO to overcome the capacity of hemoglobin to bind and inactivate NO. The identity of NO as the ultimate antimitogenic effector was further supported by the potentiation of SNAP-induced antimitogenesis by SOD, an agent that is thought to increase the chemical stability of NO by decreasing superoxide levels in oxygen-containing media $(4,6,19)$.

The antimitogenic effect of NO-generating agents was unlikely to be due to NO-induced cell damage, based on the finding that $1 \mathrm{mM}$ SNAP did not cause the release of lactate dehydrogenase or decrease cell number after $22 \mathrm{~h}$ of incubation. Moreover, the inhibition of cell proliferation induced by $0.1 \mathrm{mM}$ SNAP in long-term experiments was also unlikely to be the result of toxicity and damage to cells as shown by the lack of lactate dehydrogenase release into the extracellular medium, the lack of staining by trypan blue and the lack of cell detachment. Concentrations of SNAP higher than $0.1 \mathrm{mM}$ SNAP did however induce a decrease of cell number in longterm experiments, indicating the potential for cell damage by either SNAP or SNAP-degradation products at relatively high concentrations.

Most, if not all, of the antimitogenic effect of NO-generating agents appeared to be the result of a direct interaction with cells rather than degradation of serum mitogens, based on the finding that preincubated SNAP-containing culture medium regained most of its mitogenic activity. The residual inhibition of mitogenesis by degraded SNAP could be due to SNAP degradation products that include nitrite and nitrate, the former of which is a potential NO precursor and could conceivably generate additional NO, by sulfhydryl-catalyzed reactions (9). It is also possible that the dimer of $N$-acetylpenicillamine, thought to be generated as a result of SNAP degradation, could inhibit mitogenesis. Still another possibility is that NO, particularly at higher concentrations, did cause some degradation of serum mitogens.

The ability of 8-bromo-cGMP to mimic the antimitogenic effect of NO-generating vasodilators provided preliminary evidence in support of the notion that at least a portion of this effect was likely to be mediated by cGMP as the second messenger. Moreover, this finding also provided further support for the notion that most of the antimitogenic effect was not due to cell toxicity or to degradation of serum mitogens by free radical mechanisms since 8-bromo-cGMP would not be expected to generate free radicals.

Excessive vascular smooth muscle proliferation is considered to be a hallmark of atherosclerotic disease (20-22) and the experimental removal of endothelium has been associated with proliferation of the underlying vascular smooth muscle cells (23-25). It has therefore been postulated that one of the functions of endothelial cells is to maintain the mitogenic qui- 
escence of the underlying medial vascular smooth muscle cells. Recent studies have also demonstrated the tonic generation of NO and EDRF by endothelial cells $(8,26)$. These results, taken together with our present observations, support the possibility that endogenous NO may play an important role as modulator of smooth muscle cell growth and that the lack of endogenous NO might induce excessive proliferation of these cells, consequent to the removal of a tonic inhibitory influence.

\section{Acknowledgments}

We thank Dr. R. Seshadri for assistance in characterizing SNAP.

This work was supported by National Institutes of Health grants HL 33769 and HL 34304, a grant-in-aid from the American Heart Association, Tennessee Affiliate, Career Development Award HL-01082 (to A. Hassid), and a fellowship from the American Heart Association, Tennessee Affiliate (U. C. Garg).

\section{References}

1. Furchgott, R. F., P. D. Cherry, J. V. Zawadzki, and D. Jothianandan. 1984. Endothelial cells as mediators of vasodilation of arteries. J. Cardiovasc. Pharmacol. 6:S336-S343.

2. DeMey, J. G., M. Claeys, and P. M. Vanhoutte. 1982. Endothelium-dependent inhibitory effects of acetylcholine, adenosine triphosphate, thrombin and arachidonic acid in the canine femoral artery. $J$. Pharmacol. Exp. Ther. 222:166-173.

3. Secrest, R. J., and B. M. Chapnick. 1988. Endothelial-dependent relaxation induced by leukotrienes $\mathrm{C}_{4}, \mathrm{D}_{4}$, and $\mathrm{E}_{4}$ in isolated canine arteries. Circ. Res. 62:983-991.

4. Ignarro, L. J., R. E. Byrns, G. G. Buga, K. S. Wood, and G. Chaudhuri. 1988. Pharmacological evidence that endothelium-derived relaxing factor is nitric oxide: use of pyrogallol and superoxide dismutase to study endothelium-dependent and nitric oxide-elicited vascular smooth muscle relaxation. J. Pharmacol. Exp. Ther. 244:181-189.

5. Ignarro, L. J., G. M. Buga, K. S. Wood, R. E. Byrns, and G. Chaudhuri. 1987. Endothelium-derived relaxing factor produced and released from artery and vein is nitric oxide. Proc. Natl. Acad. Sci. USA. 84:9265-9269.

6. Palmer, R. M. J., A. G. Ferrige, and S. Moncada. 1987. Nitric oxide release accounts for the biological activity of endothelium-derived relaxing factor. Nature (Lond.). 327:524-526.

7. Palmer, R. M. J., D. S. Ashton, and S. Moncada, S. 1988. Vascular endothelial cells synthesize nitric oxide from L-arginine. $\mathrm{Na}$ ture (Lond.). 333:664-666.

8. Kelm, M., M. Feelisch, R. Spahr, H.-M. Piper, E. Noack, and J. Schrader. 1988. Quantitative and kinetic characterization of nitric oxide and EDRF released from cultured endothelial cells. Biochem. Biophys. Res. Commun. 154:236-244.

9. Ignarro, L. J., H. Lippton, J. C. Edwards, W. H. Baricos, A. L. Hyman, P. J. Kadowitz, and C. A. Gruetter. 1981. Mechanism of vascular smooth muscle relaxation by organic nitrates, nitrites, nitroprusside and nitric oxide: Evidence for the involvement of S-nitrosothiols as active intermediates. J. Pharmacol. Exp. Ther. 218:739749.

10. Rapoport, R. M., and F. Murad. 1983. Endothelium-dependent and nitrovasodilator-induced relaxation of vascular smooth mus- cle: role of cyclic GMP. J. Cyclic Nucleotide Protein Phosphorylation Res. 9:281-296.

11. Schröder, H., E. Noack, and R. Müller. 1985. Evidence for a correlation between nitric oxide formation by cleavage of organic nitrates and activation of guanylate cyclase. J. Mol. Cell. Cardiol. 17:931-934.

12. Feelisch, M., and E. Noack. 1987. Nitric oxide (NO) formation from nitrovasodilators occurs independently of hemoglobin or nonheme iron. Eur. J. Pharmacol. 142:465-469.

13. Martin, W., G. M. Villani, D. Jothianandan, and R. F. Furchgott. 1985. Selective blockade of endothelium-dependent and glyceryl-trinitrate-induced relaxation by hemoglobin and by methylene blue in the rabbit aorta. J. Pharmacol. Exp. Ther. 232:708-716.

14. Johnson, A., F. Lermioglu, U. C. Garg, R. Morgan-Boyd, and A. Hassid. 1988. A novel biological effect of atrial natriuretic hormone: Inhibition of mesangial cell mitogenesis. Biochem. Biophys. Res. Commun. 152:893-897.

15. Field, L., R. V. Dilts, R. Ravichandran, P. G. Lenhert, and G. E. Carnahan. 1978. An unusually stable thionitrite from $\mathrm{N}$-acetylD,L-penicillamine: X-ray crystal and molecular structure of 2-acetylamino-2-carboxyl-1,1-dimethylethyl thionitrite. J. Chem. Soc. Perkin Trans. I 249-250.

16. Hassid, A. 1986. Atriopeptin II decreases cytosolic free $\mathrm{Ca}$ in cultured vascular smooth muscle cells. Am. J. Physiol. 251:C681C686.

17. Murad, F., C. K. Mittal, W. P. Arnold, S. Katsuki, and H. Kimura. 1978. Guanylate cyclase: activation by azide, nitro compounds, nitric oxide, and hydroxyl radical and inhibition by hemoglobin and myoglobin. Adv. Cyclic Nucleotide Res. 9:145-158.

18. Gruetter, C. A., B. K. Barry, D. B. McNamara, D. Y. Gruetter, P. J. Kadowitz, and L. J. Ignarro. 1979. Relaxation of bovine coronary artery and activation of coronary arterial guanylate cyclase by nitric oxide, nitroprusside and a carcinogenic nitrosoamine. J. Cyclic $\mathrm{Nu}$ cleotide Res. 5:211-224.

19. Rubanyi, G. M., and P. M. Vanhoutte. 1986. Superoxide anions and hyperoxia inactivate endothelium-derived relaxing factor. Am. J. Physiol. 250:H822-H827.

20. Ross, R. 1987. Growth factors in the pathogenesis of atherosclerosis. Acta Med. Scand. Suppl. 715:33-38.

21. Schwartz, S. M., G. R. Campbell, and J. H. Campbell. 1986. Replication of smooth cells in vascular disease. Circ. Res. 58:427-444.

22. Gordon, D., and S. M. Schwartz. 1987. Replication of arterial smooth muscle cells in hypertension and atherosclerosis. Am. J. Cardiol. 59:44A-48A

23. Clowes, A. W., M. A. Reidy, and M. M. Clowes. 1983. Kinetics of cellular proliferation after arterial injury. I. Smooth muscle growth in the absence of endothelium. Lab. Invest. 49:327-333.

24. Fishman, J. A., G. B. Ryan, and M. J. Karnovsky. 1975. Endothelial regeneration in the rat carotid artery and the significance of endothelial denudation in the pathogenesis of myointimal thickening. Lab. Invest. 32:339-351.

25. Goldberg, I. D., M. B. Stemerman, B. J. Ransil, and R. L. Fuhro. 1980. In vivo aortic muscle cell growth kinetics: differences between thoracic and abdominal segments after intimal injury in the rabbit. Circ. Res. 47:182-189.

26. Rubanyi, G. M., J. C. Romero, and P. M. Vanhoutte. 1986. Flow-induced release of endothelium-derived relaxing factor. Am. J. Physiol. 250:H1145-H1149. 